\title{
Women's Empowerment and Choice of Contraceptive Methods in Selected African Countries
}

\begin{abstract}
CONTEXT: It is generally believed that women's lack of decision-making power may restrict their use of modern contraceptives. However, few studies have examined the different dimensions of women's empowerment and contraceptive use in African countries.
\end{abstract}

\begin{abstract}
METHODS: Data came from the latest round of Demographic and Health Surveys conducted between 2006 and 2008 in Namibia, Zambia, Ghana and Uganda. Responses from married or cohabiting women aged 15-49 were analyzed for six dimensions of empowerment and the current use of female-only methods or couple methods. Bivariate and multivariate multinomial regressions were used to identify associations between the empowerment dimensions and method use.
\end{abstract}

RESULTS: Positive associations were found between the overall empowerment score and method use in all countries (relative risk ratios, 1.1-1.3). In multivariate analysis, household economic decision making was associated with the use of either female-only or couple methods (1.1 for all), as was agreement on fertility preferences (1.3-1.6) and the ability to negotiate sexual activity (1.1-1.2). In Namibia, women's negative attitudes toward domestic violence were correlated with the use of couple methods (1.1).

CONCLUSIONS: Intervention programs aimed at increasing contraceptive use may need to involve different approaches, including promoting couples' discussion of fertility preferences and family planning, improving women's self-efficacy in negotiating sexual activity and increasing their economic independence.

International Perspectives on Sexual and Reproductive Health, 2012, 38(1):23-33, doi: 10.1363/3802312
By Mai Do and
Nami Kurimoto

Mai Do is assistant professor, and Nami Kurimoto was a doctoral candidate at the time of this study, both in the Department of Global Health Systems and Development, Tulane University School of Public Health and Tropical Medicine, New Orleans, Louisiana, USA.
Since the 1994 International Conference on Population and Development, women's empowerment has been recognized as important to their access to reproductive health services, including family planning. Women's lack of power restricts their ability to make decisions about family planning practice, as well as to have an open discussion with their partners about it. ${ }^{1,2}$

The purpose of this study was to identify associations between women's empowerment and the use of contraceptives in selected African countries. Specifically, we examined whether women's empowerment was associated with the likelihood that a couple used either a female or a couple method of contraception. In this study, female-only methods included the pill, IUD, injectable and implant; couple methods included male and female condoms, the diaphragm, foam, jelly, withdrawal, the lactational amenorrhea method and periodic abstinence-that is, methods that require at least the awareness of and a certain degree of support and cooperation from husbands. We hypothesized that women who are more empowered would be more likely to use any method, as well as female-only methods, compared with women who are not empowered. We also hypothesized that some empowered women may be more likely to involve their husband in family planning and, therefore, be more likely to use couple methods. In addition, we explored the influence of different dimen- sions of women's empowerment on contraceptive use, which generally has not been explicitly examined.

\section{WOMEN'S EMPOWERMENT \\ Definitions and Measurements}

To date, there is considerable variation in the definition and conceptualization of women's empowerment. ${ }^{3-5}$ The World Bank defines empowerment as the "expansion of freedom of choice and action to shape one's life." This definition encompasses two features of women's empowerment: process of change (through which a woman gains power in making decisions) and agency. ${ }^{7,8}$ Kabeer defines women's empowerment as a "process by which those who have been denied the ability to make strategic life choices acquire such an ability." (p. 435) This definition involves resources and achievements, in addition to process of change and agency, all of which are interrelated. A common underlying feature of these definitions is the recognition that household and interfamilial relations are central aspects of women's empowerment. Cutting-edge empirical research often incorporates analyses of empowerment that use data aggregated from individual and household levels or direct measures at the community and societal levels. ${ }^{7,10-12}$

The measurement of women's empowerment is difficult: first, because it is a process; second, because it is 
multidimensional; and third, because the concept operates at various levels. ${ }^{13}$ Until recently, women's empowerment was often measured by proxies, such as education, employment and knowledge. These characteristics are important but conceptually distant, and they do not always reflect empowerment. ${ }^{7,12,14-16}$

Among the many frameworks developed to measure women's empowerment, that proposed by Malhotra, Schuler and Boender, ${ }^{17}$ and later by Malhotra and Schuler, ${ }^{7}$ is one of the most comprehensive, in which empowerment is measured in several dimensions and at different levels. This framework suggests that women's empowerment could be exercised in six different arenas: economic, sociocultural, familial and interpersonal, legal, political and psychological. Moreover, these arenas can be examined at the household, community and broader societal levels by a series of indicators within each category.

\section{Empowerment and Contraceptive Use}

A sizable body of literature exists on the relationships between women's empowerment and contraceptive use. Blanc ${ }^{1}$ suggested that the balance of power in sexual relationships had an influence on the use of health services, which in turn could be linked to reproductive health outcomes. She proposed a framework depicting the relationships between power within sexual relationships and sexual and reproductive health outcomes. Findings consistent with that framework have been reported in a number of studies examining contraceptive and condom use. ${ }^{18-21}$

A few studies have examined other dimensions of women's empowerment, including decision making regarding household economy and family size, whether women need permission to go out, coercion or control of women by their spouse or family, women's political and legal awareness, and their participation in public protests and political campaigning. ${ }^{11,22}$ Al Riyami, Afifi and Mabry ${ }^{23}$ found associations between women's unmet need for contraception and some measures of their involvement in decision making and freedom of movement. In addition, Govindasamy and Malhotra ${ }^{24}$ found that among Egyptian women, having freedom of movement, having at least some control in household matters and budget decisions, and being involved in family planning decision making were all positively related to current use of contraceptives.

Other research has examined the relative weight of each partner's fertility preferences on contraceptive use. ${ }^{25,26}$ Another study found that both spouses' fertility intentions were associated with fertility behavior, depending on the number of children a couple already had. ${ }^{27}$ Bankole and Singh, ${ }^{28}$ in a study of 18 developing countries, determined that the use of modern contraceptives was highest when both partners agreed to stop childbearing and lowest when both wanted more children.

Fears of domestic and intimate partner violence have been reported in many settings as a barrier to contraceptive use. ${ }^{29-31}$ The use of female methods of contraception, such as the pill, may raise the male partner's suspicion of infidelity, as well as challenge his authority. ${ }^{31}$ In Africa, evidence of the relationship between domestic violence and contraceptive use remains scarce, with the exception of Alio et al., who found that women who had experienced intimate partner violence were more likely than others to report contraceptive use. ${ }^{32}$ Finally, in areas where wives' decision making is limited, family planning is not widespread, and there are differences in husbands' and wives' fertility preferences, as well as reports of substantial clandestine use of contraception. .,33-35 $^{2}$

\section{METHODS}

\section{Country Selection}

Countries were selected using the following criteria: substantial contraceptive use among married or cohabiting women (prevalence of $20 \%$ or more); an adequate sample of married or cohabiting women; comparable questions on six dimensions of women's empowerment that may be associated with contraceptive use; and a Demographic and Health Survey (DHS) conducted within the last five years (i.e., 2006 or later). Five countries-Ghana, Namibia, Uganda, Zambia and Zimbabwe-met these criteria. Zimbabwe was later excluded because most contraceptive users relied on the pill ( $72 \%$ of all married women using a method), and the use of couple methods was too limited (only 4\%) to allow meaningful analyses. ${ }^{36}$

\section{Country Settings}

The four countries included in this study have several similarities and differences. First, their family planning programs and activities began decades ago, when population growth and high fertility rates were recognized by the respective governments as a development issue. With the exception of Uganda, where the government's support for family planning began later than in other countries and remains limited, the other governments have a strong commitment to lowering fertility and increasing contraceptive use. $^{37-41}$

Second, in all four countries, knowledge of contraceptives was nearly universal, ${ }^{38,42-44}$ and ever-use of methods was usually high. Eighty-four percent of married women and $77 \%$ of married men had ever used any modern method of contraception in Namibia; ${ }^{42}$ the corresponding proportions were $50 \%$ and $56 \%$ in Ghana, ${ }^{43} 68 \%$ and $67 \%$ in Zambia, ${ }^{44}$ and $38 \%$ and $39 \%$ in Uganda. ${ }^{38}$ The current use of contraceptives varied widely across countries. At the time of the most recent DHS, the use of any method (including sterilization) among married women was 24\% in Ghana and Uganda, 41\% in Zambia and 55\% in Namibia. ${ }^{38,42-44}$

Third, in the study countries, men's negative attitudes toward contraceptive use have been documented. Fortythree percent of Namibian men and $46 \%$ of Ghanaian men believed that a woman who uses contraceptives may become promiscuous (some women also opposed contraception for fears of side effects or spousal disapproval). ${ }^{42,43}$ Many men in Ghana and Zambia were concerned about 
control over their wives' reproductive behavior, and hence the achievement of their own desire for a large family., ${ }^{2,33}$ In addition, some men (as well as women) were concerned that the availability of contraceptives could encourage negative sexual behaviors, such as early sexual initiation and adultery. ${ }^{45}$ In Uganda, Wolff et al. $^{46}$ found that men's opposition to contraception was associated with an increase in women's unmet need, as well as increased reliance on traditional methods instead of modern ones.

A fourth similarity among the included countries is that, as elsewhere in Sub-Saharan Africa, contraceptive use is strongly influenced by men's opinions and couple dynamics. In Zambia, according to Susu et al., ${ }^{47}$ two in five women who were not practicing family planning said their husband's disapproval was a reason for not using contraceptives. Another study found that covert contraceptive use among women was strongly associated with difficulties in spousal communication about contraception. ${ }^{33}$ Ezeh $^{48}$ also found that husband's disapproval was a common reason for married women in Ghana to not use a method for fear that they would lose his affection. Other studies in Ghana have suggested that the promotion of family planning cannot be successful without addressing gender-related factors, and men's attitudes toward contraception, which are rooted in the society. ${ }^{2,48-50}$ Even in Namibia, where studies on family planning and fertility are limited, a multicountry study found that approval of family planning by both spouses was significantly associated with women's use of any modern method. ${ }^{51}$

In addition, many Ghanaian women who used contraceptives feared physical abuse and reprisals not only from their husband, but also from members of their extended family. ${ }^{2,48-50}$ One of these studies reported that men thought it was acceptable to beat their wife if she adopted family planning. ${ }^{48}$ In Uganda, men's disapproval of family planning was cited as a reason for not using contraceptives by some women. ${ }^{52}$ Hence, experience with domestic and intimate partner violence is also an important factor that may prevent women from practicing contraception. In one Uganda study, many participants agreed that violence against women should be expected if women's use of contraceptives was identified or even suspected.53 Another study in this country reported that more women than men ( $27 \%$ vs. $22 \%$ ) justified domestic violence if a woman adopted a contraceptive method without her husband's approval..$^{54}$

Despite these similarities, these countries vary widely in contraceptive prevalence. Namibia had the highest contraceptive prevalence (55\%), as well as the highest level of modern contraceptive use (53\%), of the study nations. ${ }^{42}$ Ghana and Uganda had the lowest contraceptive prevalence (24\%); the use of traditional methods was also more common there. ${ }^{38,43}$ The inclusion of these countries, therefore, allows us to draw different inferences and implications from any observed associations of women's empowerment with the use of different methods within different contraceptive use settings.

\section{Data}

Data came from the latest DHS conducted in each country: 2006-2007 for Namibia, 2007 for Zambia, 2008 for Ghana and 2006 for Uganda. We included women aged 15-49 who were currently married or cohabiting with their partners. Women who had been sterilized or whose husbands had been sterilized were excluded because the series of questions on fertility, family planning negotiation and choice at the time of the survey were not applicable, as such sterilization may have taken place long before the survey. The final samples included 3,235 women in Namibia, 4,241 women in Zambia, 2,902 women in Ghana and 5,193 women in Uganda.

\section{Variables}

Following Becker and Costenbader, ${ }^{55}$ we classified contraceptive use into three categories: nonuse, use of femaleonly methods and use of couple methods (see earlier definitions).

Women's empowerment was measured on the individual level and along several dimensions as suggested in earlier studies. ${ }^{7,17}$ The first two dimensions-economic and sociocultural-were similar to those used by Malhotra, Schuler and Boender. ${ }^{17}$ Economic empowerment was assessed using five questions related to a woman's income contribution relative to her husband's ( $1=$ less; $2=$ about the same; $3=$ more), decisions about how each partner's income would be used ( $1=$ =woman alone or joint decision; $0=$ other) and decisions about major and daily household purchases (1=woman alone or joint decision; $0=$ other). Principal components analysis was used to construct an index of economic empowerment. Sociocultural empowerment was measured by asking women who decided whether they could visit their family and relatives ( 1 =woman alone or joint decision; $0=$ other).

The familial and interpersonal dimensions of women's empowerment are more complex than the first two dimensions and can be measured by a number of indicators related to domestic decision making, control over sexual relations, marriage, fertility, contraception, health-seeking behavior and attitudes regarding domestic violence. ${ }^{17}$ Some of these components may be directly related to contraceptive use, while others may not. We examined four of these dimensions of women's empowerment: healthseeking behavior, agreement on fertility preferences, negotiation regarding sexual activity and attitudes toward domestic violence.

Each of the first two dimensions was measured by a single question: who made decisions about health care for the woman ( 1 =woman alone or joint decision; $0=$ other), and whether the woman thought she and her partner wanted the same number of children ( $1=y e s ; 0=$ no or don't know). While the latter is not a perfect measure, perceived agreement in desired fertility can be an indication of spousal discussion and negotiation related to fertility.

The last two dimensions of women's empowerment were measured by a series of yes-or-no questions. For ne- 
gotiation of sexual activity, we used a series of six questions on whether the woman herself felt she was able to refuse to have sex with her partner and to ask him to use a condom in various circumstances, or whether a woman was justified in doing so ( $1=y e s ; 0=$ no; only five questions were used in Uganda). Women's attitudes regarding domestic violence were measured using five questions about whether they believed it was justifiable for a man to beat his wife or partner in specific situations. For example, "Is a [husband/partner] justified in beating his [wife/partner] if she goes out without telling him?" A woman who responded no was considered to have a negative attitude toward domestic violence. It should be noted that these questions asked about women's attitudes toward such beatings, rather than their actual experience of domestic violence. We used principal components analysis to construct indices for the negotiation of sexual activity and domestic violence measures. Thus, six indicators of women's empowerment

\begin{tabular}{|c|c|c|c|c|}
\hline Characteristic & $\begin{array}{l}\text { Namibia } \\
(\mathrm{N}=3,235)\end{array}$ & $\begin{array}{l}\text { Zambia } \\
(\mathrm{N}=4,241)\end{array}$ & $\begin{array}{l}\text { Ghana } \\
(\mathrm{N}=2,902)\end{array}$ & $\begin{array}{l}\text { Uganda } \\
(\mathrm{N}=5,193)\end{array}$ \\
\hline \multicolumn{5}{|l|}{ INDIVIDUAL } \\
\hline $15-24$ & 16.7 & 27.0 & 17.6 & 29.4 \\
\hline $25-39$ & 60.1 & 56.6 & 58.9 & 54.0 \\
\hline $40-49$ & 23.2 & 16.4 & 23.5 & 16.6 \\
\hline \multicolumn{5}{|l|}{ Educational level } \\
\hline None & 12.6 & 13.0 & 30.0 & 24.8 \\
\hline Primary & 30.8 & 61.3 & 22.3 & 60.2 \\
\hline Secondary & 47.6 & 21.7 & 44.2 & 11.8 \\
\hline$\geq$ secondary & 9.1 & 4.0 & 3.6 & 3.2 \\
\hline \multicolumn{5}{|l|}{ Household wealth tertile } \\
\hline Poorest & 33.1 & 40.9 & 31.9 & 35.7 \\
\hline Middle & 30.4 & 31.5 & 34.0 & 36.9 \\
\hline Richest & 36.5 & 27.6 & 34.0 & 27.4 \\
\hline \multicolumn{5}{|l|}{ Religion } \\
\hline Catholic & 22.1 & na & 12.5 & 43.9 \\
\hline Protestant & 74.9 & 78.6 & na & 33.3 \\
\hline Pentecostal & na & na & 35.2 & na \\
\hline Other Christian & na & na & 26.0 & na \\
\hline None/other & 3.0 & 21.4 & 26.2 & 22.8 \\
\hline Mean no. of living children (range) & $\begin{array}{c}2.8 \\
(0-12)\end{array}$ & $\begin{array}{c}3.4 \\
(0-13)\end{array}$ & $\begin{array}{c}3.0 \\
(0-11)\end{array}$ & $\begin{array}{c}3.8 \\
(0-14)\end{array}$ \\
\hline \multicolumn{5}{|c|}{ Exposure to family planning messages in mass media } \\
\hline No & 41.1 & 56.5 & 31.3 & 39.6 \\
\hline Yes & 58.9 & 43.5 & 68.7 & 60.4 \\
\hline Mean no. of methods known (range) $\dagger$ & $\begin{array}{c}5.1 \\
(0-9)\end{array}$ & $\begin{array}{c}6.1 \\
(0-10)\end{array}$ & $\begin{array}{c}6.4 \\
(0-10)\end{array}$ & $\begin{array}{c}5.0 \\
(0-8)\end{array}$ \\
\hline \multicolumn{5}{|l|}{ COMMUNITY } \\
\hline \multicolumn{5}{|l|}{ Residence } \\
\hline Rural & 52.1 & 65.6 & 57.9 & 87.0 \\
\hline Urban & 47.9 & 34.4 & 42.2 & 13.0 \\
\hline Contraceptive prevalence (range) $+\neq$ & $\begin{array}{l}41.4 \\
(7.5-82.1)\end{array}$ & $\begin{array}{l}27.9 \\
(0.0-61.5)\end{array}$ & $\begin{array}{l}17.5 \\
(5.5-25.8)\end{array}$ & $\begin{array}{l}15.7 \\
(0.0-51.7)\end{array}$ \\
\hline
\end{tabular}

†Includes the pill, IUD, injectable, implant, male and female condoms, diaphragm, foam, jelly, withdrawal, the lactational amenorrhea method and periodic abstinence. $\neq$ Among all women in the community aged 15-49, regardless of union status. Notes: All figures are percentages unless noted otherwise. na=not applicable. were used in this study: Three were continuous indices and three were categorical. An overall empowerment index was constructed from the six measures using principal components analysis.

Reliability coefficients for the different empowerment measures and the overall score ranged from 0.60 to 0.86 , indicating reasonable to high levels of correlation among components.

\section{Sample Characteristics}

The individual and community characteristics of these samples are presented in Table 1. Individual-level variables included age, educational level, household wealth, religious affiliation, number of living children, exposure to family planning messages in mass media (newspapers, radio and TV) and knowledge of modern contraceptives (number of methods known). Community-level variables included rural versus urban residence and the prevalence of contraceptive use in the community; the latter was calculated by aggregating information from individual women (regardless of union status) in each community, excluding respondents. This measure was included as a proxy for contraceptive use norms, which have been shown to be associated with individual contraceptive behavior; ${ }^{56,57}$ in addition, as posited by social network theory, a woman's contraceptive use may be associated with the normative behaviors in her community. ${ }^{56-59}$

\section{Analysis}

Bivariate multinomial regression was used to examine relationships between current contraceptive use and categorical as well as continuous independent variables. Multivariate multinomial regression was employed to identify associations between women's empowerment, its various dimensions and current contraceptive use, with and without controlling for individual- and community-level variables that may affect the outcome. An svy set of commands was used in the Stata 11 package ${ }^{60}$ to account for the DHS cluster sampling design and to obtain standard errors of estimates that were adjusted for this design.

\section{COUNTRY FINDINGS \\ Namibia}

Half of Namibian women were using a contraceptive method at the time of the survey-36\% were using a female method, and 14\% a couple method (not shown). In multinomial regression analysis, the overall score for women's empowerment was strongly associated with contraceptive use: A one-point increase in the score was related to a 19-percent increase in the likelihood that they had used a female method rather than no method, and to a 24-percent increase in the likelihood of using a couple method instead of none (Table 2, model 1). Several empowerment dimensions were also related to method use: A one-point increase in the economic measure was positively associated with use of both female and couple methods as opposed to use of no method (relative risk ratios, 1.2 


\begin{tabular}{|c|c|c|c|c|c|c|}
\hline \multirow[t]{2}{*}{ Measure } & \multicolumn{2}{|l|}{ Model 1} & \multicolumn{2}{|c|}{ Model 2 (unadjusted) } & \multicolumn{2}{|c|}{ Model 3 (adjusted)‡ } \\
\hline & Female & Couple & Female & Couple & Female & Couple \\
\hline Overall score & $1.19(0.03)^{* * *}$ & $1.24(0.05)^{* * *}$ & na & na & na & na \\
\hline Economic & na & na & $1.15(0.03)^{* * *}$ & $1.16(0.06)^{* *}$ & $1.09(0.04)^{* *}$ & $1.05(0.06)$ \\
\hline \multicolumn{7}{|l|}{ Sociocultural activities } \\
\hline Others/partner alone (ref) & na & na & 1.00 & 1.00 & 1.00 & 1.00 \\
\hline Joint/woman alone & na & na & $1.22(0.16)$ & $1.06(0.19)$ & $1.15(0.15)$ & $0.96(0.18)$ \\
\hline \multicolumn{7}{|l|}{ Health-seeking behavior } \\
\hline Others/partner alone (ref) & na & na & 1.00 & 1.00 & 1.00 & 1.00 \\
\hline Joint/woman alone & na & na & $1.13(0.16)$ & $0.87(0.17)$ & $1.15(0.17)$ & $0.89(0.19)$ \\
\hline \multicolumn{7}{|l|}{ Agree on fertility preference } \\
\hline No (ref) & na & na & 1.00 & 1.00 & 1.00 & 1.00 \\
\hline Yes & na & na & $1.61(0.14)^{* * *}$ & $1.20(0.15)$ & $1.48(0.13)^{* * *}$ & $1.02(0.15)$ \\
\hline Sexual activity negotiation & na & na & $1.04(0.03)$ & $1.09(0.05) \dagger$ & $1.00(0.03)$ & $1.02(0.05)$ \\
\hline Domestic violence attitudes & na & na & $1.04(0.03)$ & $1.20(0.05)^{* * *}$ & $0.99(0.03)$ & $1.11(0.05)^{*}$ \\
\hline
\end{tabular}

for each-model 2), while agreement on fertility preference was correlated only with use of female methods (1.6), and a one-point increase in the score for women's attitudes toward domestic violence was related to increased use of couple methods (1.2).

When all individual and community characteristics were controlled for, Namibian women's economic empowerment and agreement on fertility preference were positively associated with the use of female methods rather than no method (relative risk ratios, 1.1 and 1.5, respectively-model 3). The use of couple methods, however, was related only to women's negative attitudes toward domestic violence (1.1).

\section{Zambia}

Nearly $40 \%$ of women in the Zambian sample were using a contraceptive at the time of the survey; the proportions using female and couple methods were roughly the same (not shown). In regression analysis, positive associations were found between the overall empowerment score and the use of both female and couple methods as opposed to no method (relative risk ratios, 1.2 and 1.1, respectively-Table 3, model 1). Among the various empowerment dimensions, spousal agreement regarding fertility preference, ability to negotiate sexual activities and negative attitudes toward domestic violence were related to method use, as each of these measures was positively associ-

\begin{tabular}{|c|c|c|c|c|c|c|}
\hline \multirow[t]{2}{*}{ Measure } & \multicolumn{2}{|l|}{ Model 1} & \multicolumn{2}{|c|}{ Model 2 (unadjusted) } & \multicolumn{2}{|c|}{ Model 3 (adjusted)‡ } \\
\hline & Female & Couple & Female & Couple & Female & Couple \\
\hline Overall score & $1.17(0.03)^{* * *}$ & $1.08(0.03)^{* *}$ & na & na & na & na \\
\hline Economic & na & na & $1.10(0.03)^{* *}$ & $1.01(0.03)$ & $1.03(0.03)$ & $1.02(0.03)$ \\
\hline \multicolumn{7}{|l|}{ Sociocultural activities } \\
\hline Others/partner alone (ref) & na & na & 1.00 & 1.00 & 1.00 & 1.00 \\
\hline Joint/woman alone & na & na & $0.99(0.12)$ & $0.80(0.09) \dagger$ & $1.01(0.13)$ & $0.97(0.12)$ \\
\hline \multicolumn{7}{|l|}{ Health-seeking behavior } \\
\hline Others/partner alone (ref) & na & na & 1.00 & 1.00 & 1.00 & 1.00 \\
\hline Joint/woman alone & na & na & $1.20(0.11) \dagger$ & $0.90(0.10)$ & $1.21(0.12) \dagger$ & $0.95(0.11)$ \\
\hline \multicolumn{7}{|l|}{ Agree on fertility preference } \\
\hline No (ref) & na & na & 1.00 & 1.00 & 1.00 & 1.00 \\
\hline Yes & na & na & $1.75(0.16)^{* * *}$ & $1.31(0.15)^{*}$ & $1.45(0.14)^{* * *}$ & $1.31(0.15)^{*}$ \\
\hline Sexual activity negotiation & na & na & $1.10(0.03)^{* *}$ & $1.11(0.04)^{* *}$ & $1.03(0.03)$ & $1.08(0.03)^{*}$ \\
\hline Domestic violence attitudes & na & na & $1.06(0.03)^{*}$ & $1.09(0.03)^{*}$ & $0.99(0.03)$ & $1.02(0.03)$ \\
\hline
\end{tabular}

${ }^{*} \mathrm{p}<.05 .{ }^{* *} \mathrm{p}<.01 .{ }^{* * *} \mathrm{p}<.001 .+\mathrm{p}<.10 . \neq$ Model 3 controls for all individual and community characteristics. Notes: Female-only methods include the pill, IUD, injectable and implant; couple methods include male and female condoms, the diaphragm, foam, jelly, withdrawal, the lactational amenorrhea method and periodic abstinence. na=not applicable. ref=reference group. 
ated with the use of female (1.1-1.8) and couple methods (1.1-1.3) in model 2. In addition, women's involvement in household economic decisions was related to use of female methods (1.1).

When individual- and community-level characteristics were controlled for, however, the associations between use of female methods and economic empowerment and negotiation over sex disappeared, as did those between domestic violence attitudes and use of either type of method (model 3). Only perceived agreement on fertility preferences remained significant for both female and couple method use: Compared with women who said their partner wanted a different number of children (or who did not know their partner's preference), those who reported agreement were $45 \%$ more likely to use a female method rather than no method, and 31\% more likely to use a couple method instead of none. Finally, the correlation between women's ability to negotiate sexual activity and their use of couple methods remained significant: A one-point increase in this scale was associated with an $8 \%$ increase in the likelihood of using a couple method.

\section{Ghana}

More than three-quarters of women in the Ghana sample were not using any contraceptives at the time of the survey; only $12 \%$ were using female methods and $10 \%$ were using couple methods (not shown). The regression analysis found that the overall empowerment score was associated with the use of couple methods rather than no method (relative risk ratio, 1.3-Table 4, model 1). Female and couple method use were each related to women's empowerment in negotiating sexual activity (1.3 for each-model 2 ). In addition, the use of female methods was associated with economic empowerment (1.1), and the use of couple methods was associated with women's negative attitudes toward domestic violence (1.2).

When individual and community characteristics were controlled for in model 3, women's ability to negotiate sexual activity remained strongly associated with both contraceptive use outcomes: An increase of one point in this empowerment score was correlated with an $18 \%$ increase in the likelihood of using a female method instead of no method, and a 13\% increase in the likelihood of using a couple method instead of no method. In this model, economic empowerment was only marginally related to use of female methods, and the association between negative attitudes toward domestic violence and use of couple methods also lost significance.

\section{Uganda}

The majority (79\%) of Ugandan women were not using any contraceptives at the time of the survey; use of female methods was twice that of couple methods ( $14 \%$ and $7 \%$, respectively-not shown). Regression analysis found that the overall score of women's empowerment had a strong relationship with contraceptive use: An increase of one point in the score was associated with a $21 \%$ increase in the relative risk of using female methods as opposed to no method, and a 31\% increase in the likelihood of using couple methods instead of no method (Table 5, model 1 ). Four of the empowerment dimensions were shown to be associated with contraceptive use. Women's economic empowerment was related to both female and couple method use (relative risk ratios, 1.2 for each-model 2). In addition, women who reported spousal agreement on fertility preferences were more likely to use female or couple methods rather than no method (1.4 and 2.0, respectively), as were those who scored higher on the scale of negative attitudes

\begin{tabular}{|c|c|c|c|c|c|c|}
\hline \multirow[t]{2}{*}{ Measure } & \multicolumn{2}{|l|}{ Model 1} & \multicolumn{2}{|c|}{ Model 2 (unadjusted) } & \multicolumn{2}{|c|}{ Model 3 (adjusted)‡ } \\
\hline & Female & Couple & Female & Couple & Female & Couple \\
\hline Overall score & $1.14(0.07) \dagger$ & $1.27(0.11)^{*}$ & na & na & na & na \\
\hline Economic & na & na & $1.14(0.07)^{*}$ & $1.11(0.10)$ & $1.10(0.05) \dagger$ & $1.02(0.09)$ \\
\hline \multicolumn{7}{|l|}{ Sociocultural activities } \\
\hline Others/partner alone (ref) & na & na & 1.00 & 1.00 & 1.00 & 1.00 \\
\hline Joint/woman alone & na & na & $1.13(0.17)$ & $0.94(0.16)$ & $1.17(0.16)$ & $0.97(0.18)$ \\
\hline \multicolumn{7}{|l|}{ Health-seeking behavior } \\
\hline Others/partner alone (ref) & na & na & 1.00 & 1.00 & 1.00 & 1.00 \\
\hline Joint/woman alone & na & na & $0.98(0.19)$ & $0.79(0.15)$ & $1.00(0.22)$ & $0.82(0.15)$ \\
\hline \multicolumn{7}{|l|}{ Agree on fertility preference } \\
\hline $\mathrm{No}(\mathrm{ref})$ & na & na & 1.00 & 1.00 & 1.00 & 1.00 \\
\hline Yes & na & na & $1.05(0.13)$ & $1.17(0.20)$ & $1.04(0.11)$ & $1.06(0.14)$ \\
\hline Sexual activity negotiation & na & na & $1.26(0.09)^{* *}$ & $1.28(0.07)^{* * *}$ & $1.18(0.07)^{*}$ & $1.13(0.05)^{*}$ \\
\hline Domestic violence attitudes & na & na & $0.96(0.05)$ & $1.21(0.07)^{* *}$ & $0.95(0.04)$ & $1.11(0.06) \dagger$ \\
\hline
\end{tabular}

${ }^{*} \mathrm{p}<.05 .{ }^{* *} \mathrm{p}<.01 .{ }^{* * *} \mathrm{p}<.001 .+\mathrm{p}<.10$. $\neq$ Model 3 controls for all individual and community characteristics. Notes: Female-only methods include the pill, IUD, injectable and implant; couple methods include male and female condoms, the diaphragm, foam, jelly, withdrawal, the lactational amenorrhea method and periodic abstinence. na=not applicable. ref=reference group. 


\begin{tabular}{|c|c|c|c|c|c|c|}
\hline \multirow[t]{2}{*}{ Measure } & \multicolumn{2}{|l|}{ Model 1} & \multicolumn{2}{|c|}{ Model 2 (unadjusted) } & \multicolumn{2}{|c|}{ Model 3 (adjusted)‡ } \\
\hline & Female & Couple & Female & Couple & Female & Couple \\
\hline Overall score & $1.21(0.03)^{* * *}$ & $1.31(0.06)^{* * *}$ & na & na & na & na \\
\hline Economic & na & na & $1.20(0.03)^{* * *}$ & $1.20(0.05)^{* * *}$ & $1.09(0.03)^{* *}$ & $1.09(0.04)^{*}$ \\
\hline \multicolumn{7}{|l|}{ Sociocultural activities } \\
\hline Others/partner alone (ref) & na & na & 1.00 & 1.00 & 1.00 & 1.00 \\
\hline Joint/woman alone & na & na & $1.12(0.13)$ & $1.17(0.17)$ & $1.11(0.14)$ & $1.11(0.17)$ \\
\hline \multicolumn{7}{|l|}{ Health-seeking behavior } \\
\hline Others/partner alone (ref) & na & na & 1.00 & 1.00 & 1.00 & 1.00 \\
\hline Joint/woman alone & na & na & $0.91(0.09)$ & $1.01(0.14)$ & $1.07(0.12)$ & $1.13(0.16)$ \\
\hline \multicolumn{7}{|l|}{ Agree on fertility preference } \\
\hline No (ref) & na & na & 1.00 & 1.00 & 1.00 & 1.00 \\
\hline Yes & na & na & $1.40(0.14)^{* *}$ & $1.99(0.22)^{* * *}$ & $1.20(0.12) \dagger$ & $1.60(0.18)^{* * *}$ \\
\hline Sexual activity negotiation & na & na & $1.09(0.05) \dagger$ & $1.13(0.06)^{*}$ & $0.97(0.04)$ & $1.02(0.05)$ \\
\hline Domestic violence attitudes & na & na & $1.16(0.03)^{* * *}$ & $1.21(0.06)^{* * *}$ & $1.03(0.03)$ & $1.07(0.05)$ \\
\hline
\end{tabular}

toward domestic violence (1.2 for each). Empowerment in negotiating sexual activity was related only to the use of couple methods (1.1).

When all background characteristics were adjusted for, women's economic empowerment remained associated with contraceptive use: A one-point increase in the empowerment score was related to a $9 \%$ increase in the relative risk of using either female or couple methods instead of no method (model 3). However, the domestic violence measure was no longer associated with use of either type of method, and the association between women's ability to negotiate sexual activity and use of couple methods also lost significance. Finally, women who reported spousal agreement on fertility preferences were $60 \%$ more likely to use couple methods than to use no method, while the association with use of female methods disappeared.

\section{DISCUSSION}

Most studies of women's empowerment and family planning have examined only a single or a few aspects of empowerment, a complex concept that is often difficult to measure. This study is unique in that it measured six dimensions of empowerment and identified associations between these dimensions and contraceptive practice in four African countries.

Associations between method use and the different dimensions of empowerment varied across countries, yet some findings were consistent across two or more countries. First, female-only methods were much more commonly used than couple methods in Namibia and Uganda. It should be noted that all female methods in this study were modern methods, which are more likely to be promoted by family planning programs than traditional methods, whose use made up the majority of couple method use. The observed difference between female and couple method use could be a result of the efforts of such programs over several decades.

Second, in all countries but Ghana, women's overall empowerment score was positively associated with both female and couple method use. In three of the countries, we also found that two or three empowerment dimensions were associated with contraceptive use in the multivariate analyses: economic decision making, negotiation of sexual activity and perceived agreement on fertility preferences. In several cases, one of these dimensions of empowerment was related to use of both female and couple methods. In Namibia, which had the highest contraceptive prevalence and the greatest difference between the types of methods used, contraceptive use was associated with three of the six dimensions. Furthermore, this was the only country in which both economic empowerment and agreement on fertility preferences were related to use of female-only methods.

In none of the countries was the sociocultural or healthseeking dimension associated with contraceptive use. It is possible that in these African countries, women's mobility is not as limited as it is in some Asian settings ${ }^{61}$ this is one of the limitations of current questions on women's empowerment in the standard DHS questionnaire, which were based on a conceptual framework developed mainly from experience in Asia. ${ }^{62}$ Hence the question used to measure this aspect of empowerment may not accurately capture this dimension in Africa, and questions related to other types of mobility restrictions may be more relevant. Additional qualitative research is needed to understand the specific context surrounding women's mobility and to identify appropriate indicators for this measure, as suggested by Schatz and Williams. ${ }^{62}$ 
The finding that women's empowerment in their healthseeking behavior was not linked to contraceptive use was unexpected. It is plausible that there is truly no association between this aspect of decision making and contraceptive use, because health-seeking behavior may not necessarily involve interactions with their partners, whereas method use does. Again, qualitative research is needed to improve our understanding of decision making within households: For example, what issues are considered a household matter and should be decided jointly by couples, and which are considered to involve women only? In our study, it was not clear whether women were empowered to make

More research is needed to understand the mechanisms of the associations between empowerment and contraceptive use in settings with different contraceptive prevalence rates. decisions regarding their health care, or whether they simply lived in households in which husbands or partners contributed little to issues that were not directly related to themselves. A recent qualitative study in Kenya suggested marked differences in how individuals interpreted the same questions on women's decision-making power. ${ }^{63}$

Clearly, although the DHS includes standard questions that allow cross-country comparisons, supplemental qualitative research would be helpful to better understand the contexts surrounding women's empowerment.

In addition, this study is limited by the data available to measure women's empowerment. Data came from women's responses to questions about usual practices in their household, as well as to several hypothetical questions. Hence, there is some risk of social desirability bias if women gave responses that they thought were expected, especially on sensitive issues related to sexual activity and domestic violence. Moreover, for some dimensions of empowerment, such as agreement on fertility preferences, the measure may not reflect the true situation if partners do not talk about the number of children that they want to have, or if women agree to whatever their husbands wish. Other studies have found that in settings with high gender inequality, actual fertility preference agreement may be lower than reported because societal norms may make women less likely to voice their own fertility desires, ${ }^{11,64,65}$ and women may also be more likely to agree with their partner's wishes.

Another limitation of this study is related to the crosssectional nature of DHS data. Because the data for women's empowerment and contraceptive use were collected at the time of the survey, the temporal relationship between the two variables cannot be determined. It is also possible that the same observed or unobserved factors may influence both empowerment and method use. We did control for several factors that are theoretically related to contraceptive use but not to empowerment, such as the number of methods known and the prevalence of contraceptive use at the community level. Full testing and controlling for endogeneity is desirable, but was beyond the scope of this study.

Reverse causality between women's empowerment and method use cannot be ruled out. It is plausible that some women feel empowered because contraceptive use gives them a sense of being capable of controlling their fertility.
In fact, it is possible that the use of female methods may result in increased perceived empowerment among these users; women could use female methods without any discussion with or involvement of their partners. In Namibia, this scenario cannot be ruled out: The pill and injectables were the most commonly used methods, and there was a large difference in the use of female and couple methods. Namibia was also the only study country in which we found positive associations between any dimension of empowerment and female method use only. In the other countries, empowerment was related to couple method use only, or to use of both types of method, which does not entirely support the argument of reverse causality.

The study was also restricted to married or cohabiting women, who accounted for between 36\% (in Namibia) and $63 \%$ (in Uganda) of the DHS samples. Our supplementary analyses showed that women in the study samples were less educated and less wealthy than women who were not included in this study (not shown). Because it is possible that unmarried women may be more empowered than married or cohabiting women, our results are generalizable only to women who are married or living with a partner in these four countries.

Finally, although our study employed the most recent DHS data, changes in contraceptive availability and use may have occurred in the last few years. For example, Uganda has been promoting long-acting and permanent family planning methods in some areas, and Zambia has seen a shift in funding from family planning to HIV prevention and treatment. ${ }^{66,67}$ Although these changes are unlikely to have led to shifts in contraceptive use within a short time frame, in the long term these changes may lead to increased use of long-acting methods, such as IUDs, or of couple methods, such as male condoms; consequently, the associations between empowerment and contraceptive use observed in this study may also change.

\section{Conclusions}

Despite these limitations, our study found important associations between several dimensions of women's empowerment and the choice of contraceptive methods, and these findings have a number of significant implications. More research is needed to understand the mechanisms of the associations between empowerment and contraceptive use in settings with different contraceptive prevalence rates. For example, must a threshold of contraceptive prevalence be reached before women's empowerment begins to play a role in modern contraceptive use? And does demand for family planning need to be established before associations between empowerment and method use can be observed? Other unanswered questions involve how interactions between empowerment and access to family planning services may influence the use of contraceptives. Furthermore, future studies need to take into account women's empowerment from men's perspective to better capture couples' decision-making dynamics. Finally, as mentioned earlier, more research is needed to gain insight 
into the meaning and functioning of women's empowerment in African settings.

Our findings suggest that different strategies could be employed to promote family planning in these countries. For example, in Zambia, one strategy to increase overall contraceptive use could be promoting couples' discussions about their fertility desires and involving men in decision making related to fertility and contraception. Another strategy may be to improve women's self-efficacy and attitudes related to the negotiation of sexual activity; since this dimension was related only to couple method use, it may be an effective strategy in settings where the availability of modern contraceptives, with the exception of condoms, is limited. Programs that aim to increase women's ability to negotiate sexual activity may be particularly important in Ghana, where family planning practice is not widespread. Such programs may need to be coupled with efforts to increase contraceptive availability to meet the potential for increased demand for modern methods.

In Uganda, programs aimed at improving women's independent earnings and contribution to household finances may be more important than those aimed at increasing couples' discussions of fertility. Other programs in Uganda may need to consider costs related to family planning supplies and transportation to health facilities, which could be an important factor in the use of female methods, many of which require periodic resupplies or assistance from medical professionals. It is possible that women who have some control in financial matters have better access to these services than women who have little or no control. Finally, in Namibia, the findings that women's empowerment regarding household finances and fertility preferences were associated with female methods and not couple methods may suggest that many Namibians still perceive family planning practice as a woman's responsibility. If, indeed, men have reservations about family planning, intervention programs that involve them may be more useful than programs aimed at improving women's empowerment alone. Overall, our study suggests that although women's empowerment in general is associated with increases in contraceptive use, a "one-size-fits-all" strategy for contraceptive promotion in Africa is unlikely to be effective.

\section{REFERENCES}

1. Blanc AK, The effect of power in sexual relationships on sexual and reproductive health: an examination of the evidence, Studies in Family Planning, 2001, 32(3):189-213.

2. Bawah AA et al., Women's fears and men's anxieties: the impact of family planning on gender relations in northern Ghana, Studies in Family Planning, 1999, 30(1):54-66.

3. Batliwala $S$, The meaning of women's empowerment: new concepts from action, in: Sen G, Germain A and Chen LC, eds., Population Policies Reconsidered: Health, Empowerment and Rights, Cambridge, MA, USA: Harvard Center for Population and Development Studies, 1994.

4. Bisnath S, Globalization, poverty and women's empowerment, paper presented at the United Nations Division for the Advancement of Women expert group meeting, New Delhi, Nov. 26-29, 2001.

5. Mosedale S, Assessing women's empowerment: towards a concep- tual framework, Journal of International Development, 2005, 17(2): 243-257.

6. Narayan D, ed., Empowerment and Poverty Reduction: A Sourcebook, Washington, DC: World Bank, 2002

7. Malhotra A and Schuler SR, Women's empowerment as a variable in international development, in: Narayan D, ed., Measuring Empowerment: Cross-Disciplinary Perspectives, New Delhi: Oxford University Press, 2005.

8. Pradhan B, Measuring empowerment: a methodological approach, Development, 2003, 46(2):51-57.

9. Kabeer N, The conditions and consequences of choice: reflections on the measurement of women's empowerment, Discussion Paper Geneva: United Nations Research Institute for Social Development, 1999, No. 108.

10. Jejeebhoy SJ and Sathar ZA, Women's autonomy in India and Pakistan: the influence of religion and region, Population and Development Review, 2001, 27(4):687-712.

11. Mason KO and Smith HL, Husbands' versus wives' fertility goals and use of contraception: the influence of gender context in five Asian countries, Demography, 2000, 37(3):299-311.

12. Mason KO and Smith HL, Women's Empowerment and Social Context: Results from Five Asian Countries, Washington, DC: World Bank, 2003

13. Alsop R, Bertelsen MF and Holland J, Empowerment in Practice: From Analysis to Implementation, Washington, DC: World Bank, 2006.

14. Kabeer N, Gender equality and women's empowerment: a critical analysis of the third Millennium Development Goal, Gender and Development, 2005, 13(1):13-24.

15. Kishor S, Autonomy and Egyptian women: findings from the 1988 Egypt Demographic and Health Survey, Occasional Papers, Calverton, MD, USA: Macro International, 1995, No. 2.

16. Mason KO, Measuring women's empowerment: learning from cross-national research, in: Narayan D, ed., Measuring Empowerment: Cross-Disciplinary Perspectives, New Delhi: Oxford University Press, 2005

17. Malhotra A, Schuler SR and Boender C, Measuring women's empowerment as a variable in international development, background paper prepared for the World Bank Workshop on Poverty and Gender: New Perspectives, Washington, DC, June 28, 2002.

18. Harvey SM et al., Sexual decision making and safer sex behavior among young female injection drug users and female partners of IDUs, Journal of Sex Research, 2003, 40(1):50-60.

19. Pulerwitz J, Gortmaker SL and DeJong W, Measuring sexual relationship power in HIV/AIDS research, Sex Roles, 2000, 42(7-8): 637-660.

20. Wang RH and Chiou CJ, Relative contribution of intrapersonal and partner factors to contraceptive behavior among Taiwanese female adolescents, Journal of Nursing Scholarship, 2008, 40(2):131-136

21. Wingood GM and DiClemente RJ, Application of the theory of gender and power to examine HIV-related exposures, risk factors, and effective interventions for women, Health Education \& Behavior, 2000, 27(5):539-565

22. Schuler SR and Hashemi SM, Credit programs, women's empowerment, and contraceptive use in rural Bangladesh, Studies in Family Planning, 1994, 25(2):65-76.

23. Al Riyami A, Afifi M and Mabry RM, Women's autonomy, education and employment in Oman and their influence on contraceptive use, Reproductive Health Matters, 2004, 12(23):144-154.

24. Govindasamy P and Malhotra A, Women's position and family planning in Egypt, Studies in Family Planning, 1996, 27(6):328-340.

25. Dodoo FNA, Men matter: additive and interactive gendered preferences and reproductive behavior in Kenya, Demography, 1998, 35(2):229-242. 
26. Kulczycki A, Husband-wife agreement, power relations and contraceptive use in Turkey, International Family Planning Perspectives, 2008, 34(3):127-137.

27. Bankole A, Desired fertility and fertility behavior among the Yoruba of Nigeria: a study of couple preferences and subsequent fertility, Population Studies, 1995, 49(2):317-328.

28. Bankole A and Singh S, Couple's fertility and contraceptive decision-making in developing countries: hearing the man's voice, International Family Planning Perspectives, 1998, 24(1):15-24.

29. Heise L, Ellsberg M and Gottmoeller M, A global overview of gender-based violence, International Journal of Gynecology $\&$ Obstetrics, 2002, 78(Suppl. 1):S5-S14.

30. Pallitto CC and O'Campo P, The relationship between intimate partner violence and unintended pregnancy: analysis of a national sample from Colombia, International Family Planning Perspectives, 2004, 30(4):165-173.

31. Williams CM, Larsen U and McCloskey LA, Intimate partner violence and women's contraceptive use, Violence Against Women, 2008, 14(12):1382-1396.

32. Alio AP et al., Intimate partner violence and contraception use among women in Sub-Saharan Africa, International Journal of Gynecology \& Obstetrics, 2009, 107(1):35-38

33. Biddlecom AE and Fapohunda BM, Covert contraceptive use: prevalence, motivations, and consequences, Studies in Family Planning, 1998, 29(4):360-372.

34. Castle S et al., A qualitative study of clandestine contraceptive use in urban Mali, Studies in Family Planning, 1999, 30(3):231-248.

35. Fapohunda BM and Rutenberg N, Expanding Men's Participation in Reproductive Health in Kenya, Nairobi, Kenya: African Population Policy Research Center, 1999.

36. Central Statistical Office (CSO) Zimbabwe and Macro International, Zimbabwe Demographic and Health Survey, 2005-06, Calverton, MD, USA: CSO and Macro International, 2007.

37. Blacker J et al., Fertility in Kenya and Uganda: a comparative study of trends and determinants, Population Studies, 2005, 59(3): 355-373.

38. Uganda Bureau of Statistics (UBOS) and Macro International, Uganda Demographic and Health Survey, 2006, Calverton, MD, USA: UBOS and Macro International, 2007.

39. Lucas D, Fertility and family planning in southern and central Africa, Studies in Family Planning, 1992, 23(3):145-158.

40. Hong R et al., Ghana Trend Analysis for Family Planning Service, 1993, 1996, and 2002, Calverton, MD, USA: ORC Macro, 2005.

41. Oliver R, Contraceptive use in Ghana: the role of service availability, quality, and price, Living Standards Measurement Study Working Papers, Washington, DC: World Bank, 1995, No. 111

42. Ministry of Health and Social Services (MoHSS) Namibia and Macro International, Namibia Demographic and Health Survey, 200607, Windhoek, Namibia: MoHSS; and Calverton, MD, USA: Macro International, 2008

43. Ghana Statistical Service (GSS), Ghana Health Service (GHS) and ICF Macro, Ghana Demographic and Health Survey, 2008, Accra, Ghana: GSS, GHS and ICF Macro, 2009.

44. Central Statistical Office (CSO) Zambia et al., Zambia Demographic and Health Survey, 2007, Calverton, MD, USA: CSO and Macro International, 2009.

45. Chapman K and Gordon G, Reproductive health technologies and gender: is participation the key? Gender and Development, 1999, $7(2): 34-44$.

46. Wolff B, Blanc AK and Ssekamatte-Ssebuliba J, The role of couple negotiation in unmet need for contraception and the decision to stop childbearing in Uganda, Studies in Family Planning, 2000, 31(2): 124-137.

47. Susu B et al., Family planning practices before and after childbirth in Lusaka, Zambia, East African Medical Journal, 1996, 73(11):
$708-713$.

48. Ezeh AC, The influence of spouses over each other's contraceptive attitudes in Ghana, Studies in Family Planning, 1993, 24(3):163-174

49. Akafuah RA and Sossou MA, Attitudes toward and use of knowl edge about family planning among Ghanaian men, International Journal of Men's Health, 2008, 7(2):109-120.

50. Phillips JF, Bawah AA and Binka FN, Accelerating reproductive and child health programme impact with community-based services: the Navrongo experiment in Ghana, Bulletin of the World Health Organization, 2006, 84(12):949-955.

51. Gebreselassie T and Mishra V, Spousal agreement on family planning in Sub-Saharan Africa, DHS Analytical Studies, Calverton, MD, USA: Macro International, 2007, No. 11.

52. Khan S et al., Unmet Need and the Demand for Family Planning in Uganda: Further Analysis of the Uganda Demographic and Health Surveys, 1995-2006, Calverton, MD, USA: Macro International, 2008.

53. Kaye DK et al., Domestic violence as risk factor for un wanted pregnancy and induced abortion in Mulago Hospital, Kampala, Uganda, Tropical Medicine \& International Health, 2006, 11(1):90-101

54. Koenig MA et al., Domestic violence in rural Uganda: evidence from a community-based study, Bulletin of the World Health Organization, 2003, 81(1):53-60.

55. Becker S and Costenbader E, Husbands' and wives' reports of contraceptive use, Studies in Family Planning, 2001, 32(2):111-129.

56. DeGraff DS, Bilsborrow RE and Guilkey DK, Community-level determinants of contraceptive use in the Philippines: a structural analysis, Demography, 1997, 34(3):385-398.

57. Entwisle B et al., Community and contraceptive choice in rural Thailand: a case study of Nang Rong, Demography, 1996, 33(1):1-11.

58. Kincaid DL, Social networks, ideation, and contraceptive behavior in Bangladesh: a longitudinal analysis, Social Science $\&$ Medicine 2000, 50(2):215-231.

59. Valente TW et al., Social network associations with contraceptive use among Cameroonian women in voluntary associations, Social Science \& Medicine, 1997, 45(5):677-687.

60. StataCorp, Stata Statistical Software: Release 12, College Station TX, USA: StataCorp, 2011

61. Acharya DR et al., Women's autonomy in household decisionmaking: a demographic study in Nepal, Reproductive Health, 2010, $7: 15$.

62. Schatz E and Williams J, Understanding women's status, empowerment and autonomy in sub-Saharan Africa: the need to contextualize and validate DHS gender analyses with supplemental qualitative data, paper presented at the annual meeting of the Population Association of America, Washington, DC, Mar. 31-Apr. 2, 2011

63. Smith DN et al., Assessing understanding of questions from gender and power norm scales in Siaya, Kenya, paper presented at the annual meeting of the Population Association of America Washington, DC, Mar. 31-Apr. 2, 2011.

64. Mahmood N and Ringheim K, Knowledge, approval and com munication about family planning as correlates of desired fertility among spouses in Pakistan, International Family Planning Perspectives, 1997, 23(3):122-129 \& 145.

65. DeRose LF and Ezeh AC, Men's influence on the onset and progress of fertility decline in Ghana, 1988-98, Population Studies, 2005 59(2):197-210.

66. Subramanian L et al., Revitalizing long-acting and permanent methods of family planning in Uganda: ACQUIRE's district approach, Evaluation and Research Studies, New York: EngenderHealth/ The ACQUIRE Project, 2008, No. 10.

67. The ACQUIRE Project, Moving Family Planning Programs Forward: Learning from Success in Zambia, Malawi, and Ghana, New York: The ACQUIRE Project/EngenderHealth, 2005. 


\section{RESUMEN}

Contexto: Hay la creencia generalizada de que la falta de poder de toma de decisiones entre las mujeres puede restringir su uso de anticonceptivos modernos. Sin embargo, son pocos los estudios que han examinado las diferentes dimensiones del empoderamiento de la mujer y el uso de anticonceptivos en los países africanos.

Métodos: Los datos provinieron de la más reciente ronda de Encuestas de Demografía y Salud conducidas entre 2006 y 2008 en Ghana, Namibia, Uganda y Zambia. Se analizaron las respuestas de mujeres casadas o viviendo en unión consensual en edades de 15-49, con respecto a seis dimensiones de empoderamiento y el uso actual de métodos exclusivos para mujeres o métodos para la pareja. Se usaron regresiones multinomiales bivariadas y multivariadas para identificar las asociaciones entre las dimensiones de empoderamiento y el uso de métodos.

Resultados: Se encontraron asociaciones positivas entre el puntaje general del índice de empoderamiento y el uso de un método anticonceptivo en todos los países (razones de riesgo relativo, 1.1-1.3). En el análisis multivariado, el hecho de que la mujer tome decisiones económicas en el hogar se asoció con el uso de métodos, ya sea de uso exclusivo de la mujer o de la pareja (1.1 para ambos), así como con el acuerdo a nivel de pareja en las preferencias de fecundidad (1.3-1.6) y con la capacidad de negociar la actividad sexual (1.1-1.2). En Namibia, las actitudes negativas de las mujeres hacia la violencia intrafamiliar se correlacionaron con el uso de métodos que no sean exclusivamente femeninos (1.1).

Conclusiones: Las intervenciones dirigidas a aumentar el uso de anticonceptivos pueden requerir el uso de diferentes enfoques, entre ellos la promoción del diálogo en las parejas sobre las preferencias de fecundidad y el uso de la planificación familiar, el mejoramiento de la eficacia personal de las mujeres para negociar la actividad sexual y el mejoramiento de su independencia económica.

\section{RÉSUMÉS}

Contexte: Il est généralement admis que le manque de pou- voir de décision des femmes peut limiter leur pratique de la contraception moderne. Peu d'études examinent cependant les différentes dimensions de l'autonomisation des femmes et de leur pratique contraceptive dans les pays d'Afrique.

Méthodes: Les données sont issues du dernier passage de l'Enquête démographique et de santé, entre 2006 et 2008, en Namibie, en Zambie, au Ghana et en Ouganda. Les réponses des femmes de 15 à 49 ans mariées ou en concubinage sont analysées en fonction de six dimensions d'autonomisation et de la pratique actuelle de méthodes strictement féminines ou de couple. Les associations entre les dimensions d'autonomisation et la pratique d'une méthode sont identifiées par régressions multinomiales bivariées et multivariées.

Résultats: Des associations positives sont observées entre la cote d'autonomisation globale et la pratique d'une méthode dans tous les pays (rapports de risques relatifs, 1,1-1,3). Dans l'analyse bivariée, la prise de décisions économiques au sein du ménage est associée à l'usage de méthodes strictement féminines ou de couple (1,1 pour tous), de même que l'accord sur les préférences de fécondité $(1,3-1,6)$ et que la capacité de négociation de l'activité sexuelle (1,1-1,2). En Namibie, les attitudes négatives des femmes à l'égard de la violence familiale sont en corrélation avec la pratique des méthodes de couple $(1,1)$.

Conclusions: L'adoption de différentes approches pourrait être utile aux programmes d'intervention visant à accroître la pratique contraceptive, notamment la promotion de la discussion des couples sur les préférences de fécondité et la planifcation familiale, l'amélioration de l'auto-efficacité des femmes dans la négociation de l'activité sexuelle et le renforcement de leur indépendance économique.

\section{Acknowledgments}

This research was supported by the MEASURE Evaluation Population and Reproductive Health Project, funded by the U.S. Agency for International Development through cooperative agreement associate award GPO-A-00-09-00003-00. The authors thank Anastasia Gage and Janine Barden-O'Fallon for their comments on earlier versions of this article.

Author contact: mdo@tulane.edu 